\title{
Novel insights into the metabolic action of Kiss1 neurons
}

\author{
Rajae Talbi and Victor M Navarro \\ Department of Medicine, Division of Endocrinology, Diabetes, and Hypertension, Brigham and Women's Hospital and Harvard Medical School, Boston, \\ Massachusetts, USA
}

Correspondence should be addressed to V M Navarro: vnavarro@bwh.harvard.edu

\begin{abstract}
Kiss1 neurons are essential regulators of the hypothalamic-pituitary-gonadal (HPG) axis by Key Words regulating gonadotropin-releasing hormone $(\mathrm{GnRH})$ release. Compelling evidence suggests $>$ kisspeptin that Kiss1 neurons of the arcuate nucleus (Kiss1 ${ }^{\text {ARC }}$ ), recently identified as the hypothalamic $>$ metabolism GnRH pulse generator driving fertility, also participate in the regulation of metabolism $>$ food intake through kisspeptinergic and glutamatergic interactions with, at least, proopiomelanocortin $~$ energy expenditure (POMC) and agouti-related peptide (AgRP)/neuropeptide Y (NPY) neurons, located in close apposition with Kiss $1^{\text {ARC }}$. This review offers a comprehensive overview of the recent developments, mainly derived from animal models, on the role of Kiss1 neurons in the regulation of energy balance, including food intake, energy expenditure and the influence of circadian rhythms on this role. Furthermore, the possible neuroendocrine pathways underlying this effect, and the existing controversies related to the anorexigenic action of kisspeptin in the different experimental models, are also discussed.
\end{abstract}

\section{Introduction}

Reproduction is a fundamental function that ensures the perpetuation of the species. As such, reproductive activity is under the regulation of a complex central and peripheral network that forms the hypothalamic-pituitary-gonadal (HPG) axis. Within the HPG axis, reproductive function is regulated by gonadotropin-releasing hormone (GnRH) neurons located in the hypothalamus, which control the production and release of gonadotropins from the pituitary to regulate gonadal function. Major progress has been made in the understanding of the central mechanisms regulating reproductive activity with the finding that GnRH synthesis and release require the stimulatory action of kisspeptin (Kp, formerly known as metastin), a hypothalamic peptide encoded by the Kiss1 gene and produced by Kiss1 neurons. Kisspeptin signaling is of paramount importance, as humans and mice bearing mutations in Kiss1 or its receptor (Kiss1r, formerly termed GPR54) display hypogonadotropic hypogonadism, pubertal failure and are infertile $(1,2)$.
In rodents, Kiss 1 neurons are primarily located in the arcuate nucleus (Kiss1 ${ }^{\mathrm{ARC}}$ ) and the anteroventral periventricular/ periventricular nucleus (Kiss $1^{\mathrm{AVPV} / \mathrm{PeN}}$ ) and are deferentially regulated by sex steroids leading to complementary roles in maintaining reproductive success. Kiss $1^{\mathrm{AVPV} / \mathrm{PeN}}$ neurons, which are vestigial in males, have been shown to play a major role in driving the preovulatory LH surge in females in response to the positive feedback of estradiol (E2) under the control of the suprachiasmatic nucleus $(\mathrm{SCN})(3,4$, $5,6)$. In contrast, in response to the negative feedback of sex steroids, Kiss $1^{\mathrm{ARC}}$ neurons regulate the tonic release of $\mathrm{GnRH} / \mathrm{LH}$, thus relaying information about the hormonal and neuroendocrine milieu (including metabolic cues) (7). In this context, the Kiss $1^{\mathrm{ARC}}$ neuronal population co-expresses the neuropeptides neurokinin $\mathrm{B}$ (NKB) and dynorphin A (Dyn A), thereafter named KNDy neurons, which hold the hypothalamic GnRH pulse generator, essential for reproductive function (8). Moreover, Kiss $1^{\text {ARC }}$ neurons are predominantly glutamatergic $(9,10)$ and
This work is licensed under a Creative Commons Attribution-NonCommercial 4.0 International License. ded from Bioscientifica.com at 04/26/2023 07:54:03AM 
have the potential to release the fast-acting transmitter glutamate onto (1) neighboring neurons in the ARC to potentially regulate metabolism (discussed in later sections), and (2) Kiss $1^{\mathrm{AVPV} / \mathrm{PeN}}$ neurons to regulate fertility $(10,11)$. An additional population of Kiss1 neurons has been recently identified in the posterodorsal part of the medial amygdala (Kiss1 ${ }^{\mathrm{MePD}}(12)$ ), and a number of chemogenetic (13) and optogenetic (14) studies by our lab and others suggest an important role of Kiss $1^{\text {MePD }}$ signaling in the regulation of the GnRH pulse generator, besides a potential role in driving emotional and sexual behavior, pubertal timing and ovulation - at least in mice $(15,16)$.

Reproductive function is energy costly and requires a threshold of energy reserves, as situations of negative energy balance (e.g. anorexia nervosa) or excessive energy deposits (e.g. obesity, diabetes) may impair the reproductive axis. During the last decade, major progress has been made in the understanding of a wide variety of reproductive disorders that are a direct result of metabolic abnormalities. Women suffering from undernutrition display hypothalamic amenorrhea, characterized by low gonadotropin secretion and infertility (17), while obese women display high risk of miscarriage, pregnancy complications, anovulation and infertility resulting from the increased negative feedback on gonadotrophin secretion, due to the peripheral conversion of androgens to estrogen (18). In this line, women suffering from polycystic ovary syndrome (PCOS, leading to hyper activation of the gonadotropic axis) are frequently obese (17), although the causative relationship between the metabolic and the reproductive phenotypes of PCOS patients is not completely understood. Overall, it is well established that energy imbalance has severe repercussions on reproductive fitness. However, the mechanisms mediating the interaction between reproductive function and energy balance are still largely unexplored. This review provides a summary of the action of Kiss1 neurons in the bidirectional interaction between reproduction and metabolism.

\section{Kiss1 neurons as metabolic gates of fertility}

Kiss1 neurons are critical regulatory nodes that integrate metabolic cues in order to adjust reproductive function to energy stores. A number of studies have characterized the inhibitory effect that metabolic stress (e.g. food deprivation) exerts on Kiss1 gene expression, leading to the decrease in LH levels and, therefore, reproductive success, in rodents and primates, which frequently manifest with delayed or absent puberty onset and infertility $(19,20,21)$. Importantly, Kiss1 neurons are direct targets of peripheral metabolic hormones (e.g. leptin, insulin); however, the relevance of Kiss1 neurons as first order metabolic responders is questioned, given that the selective deletion of receptors for metabolic cues (e.g. leptin and insulin receptors) do not appear to impinge reproductive or metabolic functions $(22,23)$. Nonetheless, a remarkable feature of Kiss $1^{\mathrm{ARC}}$ neurons is their ability to directly communicate with neurons in the ARC that regulate hunger and satiety, suggesting the existence of a bidirectional metabolic-reproductive loop (discussed subsequently). The anorexigenic proopiomelanocortin (POMC) and orexigenic agouti-related peptide (AgRP)/ neuropeptide Y (NPY) neurons are fundamental players that regulate energy balance $(24,25)$ and also play a critical role in regulating fertility $(26,27)$. On one hand, POMC, a precursor polypeptide, is expressed in the ARC, the nucleus tractus solitarius (NTS) of the brainstem and the pituitary. POMC is cleaved into different biologically active peptides, including the alpha melanocytestimulating hormone $(\alpha-\mathrm{MSH})$, which drives satiety and increases energy expenditure through its selective binding to the melanocortin receptors, MC3R and MC4R, with MC4R being the primary receptor mediating the metabolic action of melanocortins $(28,29)$. On the other hand, the orexigenic AgRP and NPY peptides - both produced in AgRP neurons - increase food intake and decrease energy expenditure $(30,31,32)$, thus termed hunger neurons. AgRP selectively binds MC4R to prevent the anorexigenic effect of $\alpha-\mathrm{MSH}$, while NPY binds preferentially Y1 and Y5 receptors to induce its orexigenic effect (25).

POMC and AgRP neurons have been extensively studied for their role as conveyors of the metabolic state to regulate fertility. In female mice and women, MC4R deficiency is associated with a number of reproductive disorders related to advanced puberty onset, irregular ovarian cyclicity and reduced number of developed corpora lutea in ovaries $(33,34,35)$, while the activation of MC4R stimulates their libido (36). In males, MC4R does not appear to be involved in gametogenesis or gonadal steroidogenesis; however, it is involved in erectile function and sexual behavior $(37,38)$. However, despite the documented action of melanocortins on reproduction, including sexual behavior, the precise site/s of action underlying this effect remain ill-defined. In this context, 50\% of GnRH neurons, located mostly in the medial preoptic area (POA), express MC4R (39) and $70 \%$ of these GnRH cells are excited by $\alpha-\mathrm{MSH}$, acting through both MC3R and MC4R (40). However, most of 
the melanocortin actions on the HPG axis appear to be mediated through Kiss1 neurons based on the fact that: (1) Kiss1 neurons receive direct projections from $\alpha-\mathrm{MSH}$ fibers, (2) Kiss1 mRNA expression decreases in the ARC of pubertal female mice subjected to chronic inhibition of MC3R/MC4R, and (3) the stimulatory action of melanocortins on the HPG axis is blunted in kisspeptin signaling deficient mice (41). These results are in line with the presence of MC4R in a subset of Kiss1 neurons (9), suggesting a likely direct regulation of Kiss1 neurons by melanocortins.

Direct regulation of Kiss1 neurons by AgRP neurons have also been described through, at least, direct inhibitory GABAergic post-synaptic inputs (42). The relevance of this regulatory pathway is further evidenced by compelling studies in leptin deficient mouse models, which display an infertile phenotype largely derived from the increase in the activity of AgRP neurons and the subsequent reversal of the infertile phenotype after the ablation of these neurons (i.e. AgRP neurons) (42). While direct connections from AgRP to Kiss1 neurons have been demonstrated, no evidence of direct interaction between AgRP and GnRH neurons has been found, suggesting that under negative energy balance, the inhibitory action on the HPG axis exerted by AgRP neurons occurs at the level of Kiss1 neurons (and/or on upstream neuroendocrine networks), further emphasizing the critical role of Kiss1 neurons in mediating the transmission of metabolic cues onto the reproductive axis. Altogether, these data suggest that the metabolic regulation of fertility by POMC and AgRP neurons occurs mostly through their action on Kiss $1^{\mathrm{ARC}}$ neurons, which act as gatekeepers in the metabolic regulation of reproductive activity.

\section{Kiss1 neurons as active metabolic players}

Since their characterization in 2003, the neuroendocrine community has focused mostly on the neuroanatomical characterization and functional role of kisspeptin in reproduction, while the metabolic facets of this neuropeptide remained underexamined. Recent studies have aimed at closing this gap to elucidate the potential metabolic role of Kiss1 neurons. Thus, it has been demonstrated that the absence of kisspeptin signaling (Kiss1rKO mice) results in increased body weight in a sex-dependent manner and that this effect is partly independent of the presence of circulating sex steroids. Adult Kiss 1 rKO females, but not males, displayed decreased food intake but higher body weight as a consequence of reduced energy expenditure and locomotor activity, as well as impaired glucose homeostasis (43) and elevated plasma leptin levels (44). Importantly, these metabolic impairments were restored in females, but not males, in a mouse model of selective reinsertion of Kiss1r only in GnRH neurons, which prevented any changes in BW of any sex during adulthood but retained the BW changes observed in prepubertal and young adult Kiss1rKO mice. This indicates that a large component of the phenotype observed in adult Kiss1rKO mice is sex-steroid dependent. However, these mice still displayed increased insulin resistance at any age compared to controls suggesting the existence of kisspeptin-dependent mechanism in glucose homeostasis (45).

Of note, while studies in rodents support a role of Kiss1 neurons in metabolism, to date, there is no evidence of metabolic impairments in patients with kisspeptin deficiency (1, 2, 46); however, a detailed metabolic characterization of these patients has not been performed.

Overall, an active role of Kiss1 neurons in the control of energy balance has been recently demonstrated in a number of rodent studies. This effect is partly indirect through the regulation of the circulating levels of sex steroids and partly direct through the action of kisspeptin and additional co-transmitters. However, whether this direct action is mediated by the control of food intake (anorexigenic action), increase in energy expenditure, or both, remains a matter of debate. Nonetheless, this action of kisspeptin (and/or co-transmitters) as satiety signals while stimulating the reproductive axis is in line with the classic action of satiety signals, for example, melanocortins and NUCB2/Nesfatin-1 (47, 48), which get activated in situations of energetic surplus to signal the organism that enough resources for reproduction are present and it is therefore safe to shift the focus from food-seeking behaviors to reproduction.

\section{Kiss1 neurons in the regulation of food intake}

The anorexigenic effects of kisspeptin were first described in mice, as the central pharmacological administration of kisspeptin during the light cycle significantly suppressed food intake (49). However, this effect was only present in overnight fasted mice, which exhibited decreased meal frequency and total meal time during refeeding. The same kisspeptin dose was ineffective to alter food intake when tested in ad libitum fed animals (49). These data revealed, for the first time, a potentially anorexigenic role of kisspeptin in mice under negative energy balance. Similar data have also been described in the wild jerboa,

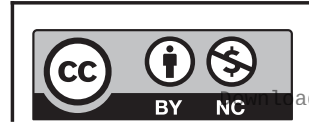

This work is licensed under a Creative Commons Attribution-NonCommercial 4.0 International License. ded from Bioscientifica.com at 04/26/2023 07:54:03AM 
where exogenous kisspeptin injections significantly inhibited food intake during refeeding in females after 48 $\mathrm{h}$ of food deprivation, but not in ad libitum fed animals (50). Importantly, this effect was present in female jerboa but not in males under any of these conditions (50), revealing that not only the anorexigenic effect of kisspeptin is dependent on the energetic state, in line with the mouse data (49), but also that this effect is sexually dimorphic. These studies go in parallel with a recent work in $24 \mathrm{~h}$ fasted rats, where kisspeptin was able to suppress food intake (51), while this effect was not observed in ad libitum fed or $12 \mathrm{~h}$ fasted animals $(19,52)$. Along this line, kisspeptin does not appear to exhibit an anorexigenic action in humans, as kisspeptin infusion in overnight fasted men did not alter appetite (53). Whether the fasted period in men was not long enough for the anorexigenic effect of kisspeptin to be evident or men are not responsive to the metabolic action of kisspeptin after acute delivery is unknown. However, given the sexual dimorphism in the metabolic effect of kisspeptin described, studies in women will be required in order to evaluate whether this response in also sexually dimorphic in humans.

In contrast to these studies described, a recent study in mice suggests that i.p. injections of kisspeptin in ad libitum fed animals suppresses food intake within the first $4 \mathrm{~h}$ following a single administration of kisspeptin and for up to $24 \mathrm{~h}$ (54). However, not only these results contradict a number of previous studies in different species suggesting that the anorexigenic action of kisspeptin, in order for it to be revealed, requires a negative energetic state but, strikingly, the long action (up to $24 \mathrm{~h}$ ) of a small peptidic compound (only ten amino-acids in kisspeptin-10) after peripheral administration is unprecedented, given that the stimulatory effect on $\mathrm{LH}$ is lost within $60 \mathrm{~min}$ of i.p. administration of high doses of kisspeptin (55). Whether Kiss1 neurons are able to elicit a cascade of events through other neurons to exert this role or there are technical aspects that affected this study requires further investigation.

While evidence on the metabolic actions of kisspeptin is mounting, the contribution of kisspeptin's partners, that is, co-transmitters released from Kiss1 neurons such as glutamate or $\mathrm{NKB}$, may enhance the overall metabolic role of Kiss1 neurons. In this context, and in line with the absence of an anorexigenic action of kisspeptin in normal fed conditions in several experimental models, a recent study of chemogenetic activation of Kiss $1^{A R C}$ neurons in fed mice failed to suppress feeding during the dark cycle over a period of $4 \mathrm{~h}$ (56).
This study suggests that none of the potential kisspeptin co-transmitters play a role in regulating food intake, at least not acutely in fed conditions. However, chronic silencing of synaptic transmission from Kiss1 $1^{A R C}$ neurons in female mice results in significant weight gain derived, in part, from feeding impairments (57). While the overall food consumed was similar to controls, the circadian feeding behavior was severely impaired, losing the nocturnal pattern of feeding observed in control mice (57). This change in the circadian rhythm of feeding correlated with similar changes in physical activity and energy expenditure. These results suggested a critical role for Kiss1 $1^{\mathrm{ARC}}$ neurons in the regulation of circadian rhythms, at least for feeding and physical activity. However, the SCN in the Kiss $1^{A R C}$ silenced mice appears to be intact and Kiss $1^{\text {ARC }}$ neurons do not project directly to the SCN (57), suggesting that Kiss $1^{\text {ARC }}$ neurons may serve as conduits for upstream signals from the SCN and/or that Kiss $1^{\text {ARC }}$ neurons control downstream targets of the SCN to modulate circadian rhythms. The latter is supported by the presence of projections from Kiss $1^{\text {ARC }}$ neurons to SCN targets involved in the regulation of circadian rhythms (i.e. subparaventricular zone (SPZ) and the dorsal medial hypothalamus $(\mathrm{DMH}))(57,58)$. These findings support a role for Kiss1 neurons in the regulation of the daily timing of food intake in a circadiandependent manner, probably contributing to the overall reduced feeding in mice during light hours. This effect is supported by the suppression of food intake after kisspeptin administration during light hours $(49,50)$ and absent during dark hours $(49,56)$. Therefore, in the face of these studies, caution should be exercised when interpreting data of kisspeptin studies on feeding behavior if time of day and basal energetic status are not properly controlled.

\section{Kiss1 neurons display bidirectional interactions with AgRP and POMC neurons}

Kiss $1^{A R C}$ neurons project to a wide variety of brain nuclei including central metabolic centers known to regulate food intake, body weight and thermogenesis: the median preoptic nucleus (MePO), bed nucleus of the stria terminalis (BnST), paraventricular nucleus of the hypothalamus (PVN), DMH and the lateral hypothalamus (LH) (58). A significant number of these Kiss $1^{\text {ARC }}$ projections also target the ARC, where hunger (AgRP) and satiety (POMC) neurons are located. In this context, initial studies supported the idea that

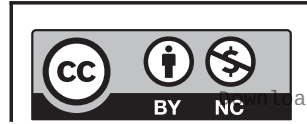

This work is licensed under a Creative Commons Attribution-NonCommercial 4.0 International License. ded from Bioscientifica.com at 04/26/2023 07:54:03AM 
Kiss $1^{\text {ARC }}$ neurons directly contact neighboring POMC and AgRP neurons. First, kisspeptin can modulate the activity of POMC neurons based on the fact that (1) POMC neurons express Kiss1r (59), (2) kisspeptin is able to excite POMC neurons through sodium/ calcium exchanger activation (60), and (3) kisspeptin increases the expression of Pomc in the ARC $(50,61)$. Second, in addition to kisspeptin input, POMC and AgRP neurons receive direct glutamatergic inputs from Kiss $1^{\text {ARC }}$ neurons that differentially regulate them in a sex-steroid-dependent manner through the activation of distinct metabotropic glutamate receptors (10). These data support a direct action of Kiss1 neurons in the regulation of essential central metabolic centers. However, the satiety inducing effect of the activation of POMC neuron activation is remarkably slow and usually requires 24 to $48 \mathrm{~h}$ to inhibit food intake (through the action of $\alpha$-MSH on MC4R) $(56,62)$. In the studies documenting the anorexigenic action of kisspeptin, the effect was observed within $1 \mathrm{~h}$ following administration $(49,50,51)$, suggesting that the anorexigenic effect is not mediated through the activation of POMC neurons. Given the fact that Kiss $1^{\text {ARC }}$ neurons are not within the glutamatergic pool of ARC neurons that targets the PVN to rapidly induce satiety (56), we can infer that kisspeptin must be acting through other 'fast acting' satiety inducing neurons as an indirect mechanism to suppress food intake. Nonetheless, the potential anorexigenic effect of kisspeptin acting through POMC neurons at a larger time scale cannot be excluded.

An important factor in the metabolic role of Kiss1 neurons relates to how much of the metabolic phenotype described to date in the different animal models is mediated by kisspeptin vs kisspeptin co-transmitters, for example, glutamate or NKB. In this context, it is worth noting that the degree of obesity observed in the Kiss $1^{\mathrm{ARC}}$-silenced female mice (57) is significantly greater, and develops faster, than that reported in Kiss1rKO mice $(43,44,45,63)$, supporting a role for additional factors from Kiss $1^{\text {ARC }}$ neurons in the control of metabolism. Importantly, glutamate has been described to mediate the effect (excitation) that Kiss $1^{\text {ARC }}$ neurons exert on POMC neurons, and to selectively inhibit AgRP neurons $(10,64)$, which strongly supports a glutamatergic component in the phenotype of the Kiss $1^{\mathrm{ARC}}$ silenced mouse model (57). Moreover, the glutamatergic action of Kiss1 neurons onto neighboring POMC and AgRP neurons is gonadal hormone dependent, as it is enhanced by $\mathrm{E} 2$ in females $(64,65)$, in line with the sex-dependent effect of kisspeptin on food intake in jerboa (50) and BW in Kiss1rKO mice (43), restricted to females (Fig. 1).

Overall, controversial data exist related to the action of kisspeptin on food intake. While the anorexigenic action of Kiss1 neurons in general, and kisspeptin in particular, cannot be ruled out under specific physiological conditions and over long periods of time, mounting evidence points to the regulation of energy expenditure, either directly or through the control of

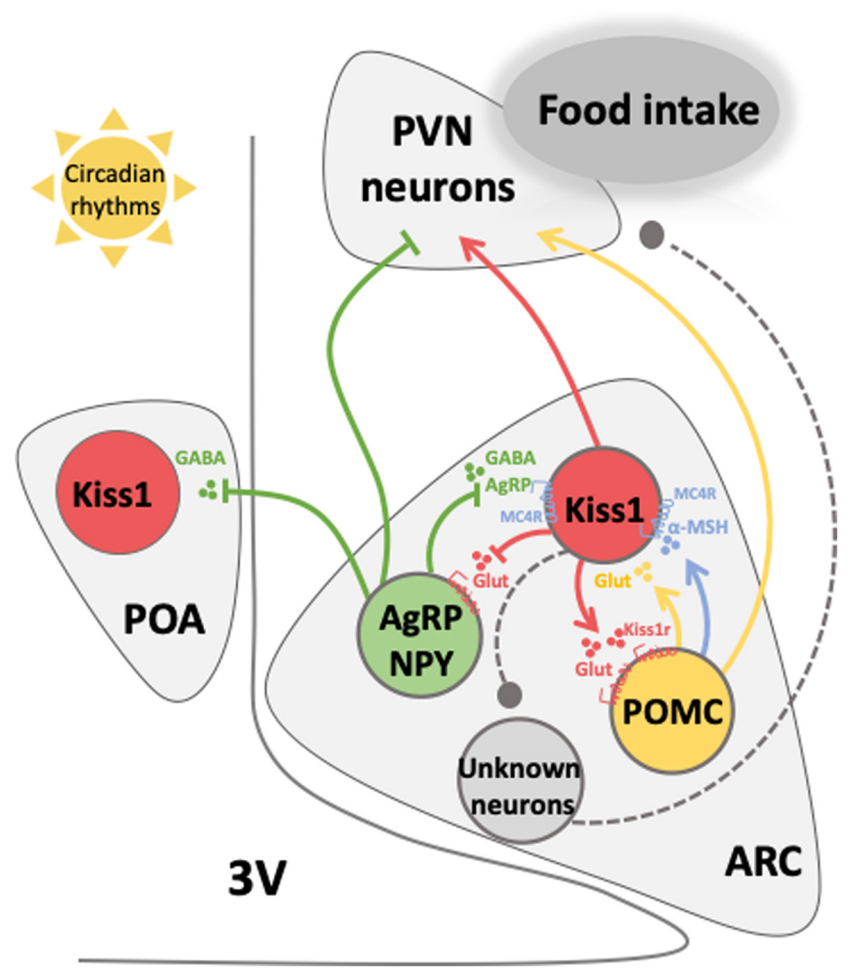

Figure 1

Schematic representation of the suggested hypothalamic neuronal network regulating food intake comprising Kiss $1^{A R C}$ neurons interactions with POMC and AgRP neurons. Neurons located in the PVN, critical for food intake regulation, receive direct projections from the ARC Kiss1, POMC and AgRP neurons. Within the ARC, Kiss1 neurons directly contact neighboring AgRP neurons to inhibit their activity through the activation of glutamate receptors on these neurons. POMC neurons, which express Kiss $1 r$, are directly stimulated by Kiss $1{ }^{\text {ARC }}$ neurons through glutamate and kisspeptin. In turn, both POMC neurons (through glutamate and $\alpha \mathrm{MSH}$ ) and AgRP neurons (through GABA and AgRP) send direct projections to Kiss1 ${ }^{\text {ARC }}$ neurons, respectively, to activate and inhibit their activity; AgRP neurons also send inhibitory GABAergic projections to Kiss $1^{\text {AVPV }}$ neurons in the preoptic area. Under the influence of circadian rhythms, Kiss 1 ARC neurons also contribute to food intake regulation through yet unknown neuroendocrine circuits. The anorexigenic effect of Kiss1 neurons might be mediated either by: (1) direct projections to PVN neurons, (2) direct stimulation to POMC neurons which, in turn, (3) inhibit food intake at the level of the PVN, and/or (4) through indirect actions on other (unknown) fast acting satiety neurons. PVN, paraventricular nucleus of the hypothalamus; 3V, third ventricle; POA, preoptic area; Glut, glutamate; MC4R, melanocortin-receptor 4 . The pointed arrows represent activations, while the flat arrows represent inhibitions. 
the rhythm of feeding behavior and locomotion as the main contributor to the overall metabolic phenotype of kisspeptin deficient models.

\section{Kiss1 neurons in the regulation of energy expenditure}

While the demonstration of an action of kisspeptin on food intake has not been consistent across the different experimental models, a critical feature shared by those models that include kisspeptin signaling deficiency (Kiss1rKO mice) or Kiss1 ${ }^{\text {ARC }}$ silencing $(43,57,63)$ has consistently been an impairment (decrease) at the energy expenditure level. In both cases, mice were less physically active, which may contribute to the loss of lean mass and increase in body fat. While this is a plausible mechanism, a direct role of Kiss $1^{\mathrm{ARC}}$ neurons in the regulation of energy expenditure through the action on central nuclei involved in this metabolic process, for example, MePO, PVN, DMH and NTS ((66), for review), which receive projections from Kiss $1^{\text {ARC }}$ neurons (58), cannot be excluded.

The contention that kisspeptin can control energy expenditure is further supported by the identification of Kiss1r in brown adipose tissue (BAT) - critical for the regulation of energy expenditure through the induction of thermogenesis - and the decrease in the activation of the BAT observed in obese Kiss $1 \mathrm{rKO}$ females (67). However, the complexity of the metabolic role of kisspeptin is further evidenced by the fact that the removal of kisspeptin signaling from the BAT increases metabolic rate and body temperature, thus decreasing body weight, which suggests that the obesity seen in Kiss1rKO and Kiss $1^{\mathrm{ARC}}$ silenced female mice is not due to the direct action of kisspeptin signaling on BAT, but rather the consequence of impaired kisspeptin signaling in other tissues involved in the regulation of energy balance. Furthermore, the source of kisspeptin that activates Kiss1r in the BAT in unknown, and since the majority of the neuronal innervation of the BAT converges into the intermediolateral nucleus of the spinal cord (IML) before reaching the BAT, the direct projection of Kiss $1^{\text {ARC }}$ neurons to this tissue is unlikely and suggests that kisspeptin acting on the BAT does not have a central origin (Fig. 2).

\section{Glucose homeostasis regulation through kisspeptin pathways}

Glucose homeostasis is maintained by the balance of insulin and glucagon secretion to control blood glucose levels. As previously mentioned, a number of studies
Circadian rhythms

\section{Energy expenditure}

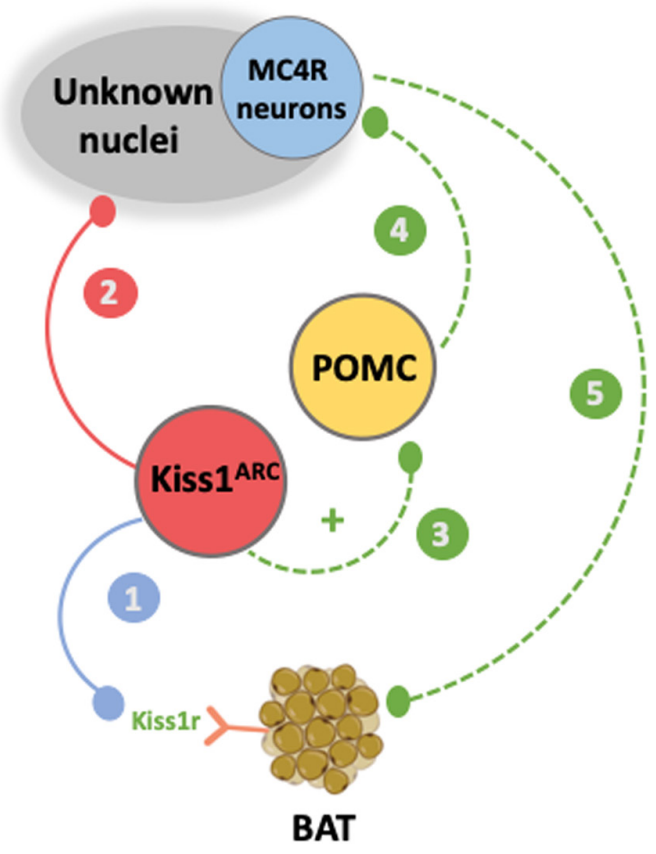

\section{Figure 2}

Hypothetical working model of the suggested hypothalamic neuronal network regulating energy expenditure comprising direct and indirect actions of Kiss1 neurons. Under the influence of circadian rhythms, Kiss $1^{A R C}$ neurons may participate in the regulation of energy expenditure through: (1) the direct action on the BAT, which expresses Kiss1r; (2) the direct action on unknown nuclei directly involved in the control of energy expenditure; or (3) through indirect actions on POMC neurons in the ARC, which (4) project onto MC4R expressing neurons in unknown nuclei to (5) regulate thermogenesis via BAT activation. BAT: brown adipose tissue. The solid lines represent Kiss1 neurons direct actions; dashed lines represent Kiss 1 neurons indirect actions through intermediate neurons.

documented that mice lacking kisspeptin signaling present impaired glucose tolerance that is not exclusively derived from their increased body weight. Both standard chow fed and high fat diet (HFD) fed Kiss1rKO female mice displayed significant glucose intolerance after a glucose tolerance test (GTT) $(43,45)$. This effect was (1) age dependent as adult, but not young 6-week-old, Kiss1rKO females displayed glucose intolerance (63), and (2) sexually dimorphic, as Kiss $1 \mathrm{r} \mathrm{KO}$ males displayed normal basal glucose levels and normal glucose tolerance both under standard chow and HFD $(43,45)$. Moreover, this effect in females is exacerbated in the absence of sex steroids, that is, in OVX Kiss1rKO females (43). Gonadal steroids (or lack thereof in Kiss1rKO mice) play a critical role in the glucose intolerance observed in the absence of kisspeptin, based on the improvement of this condition after selective restoration of Kiss1r in GnRH neurons, which normalizes

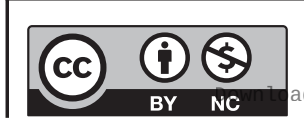


the circulating levels of sex steroids. However, this model did not rescue glucose levels completely, supporting a role of kisspeptin in additional tissues, likely at the level of the liver and/or pancreatic cells (68). Indeed, increasing evidence supports a role of kisspeptin signaling in pancreatic function based on (1) the presence of Kiss1 and Kiss $1 \mathrm{r}$ in pancreatic $\beta$ and $\alpha$ cells (68), and (2) the in vitro exposure of monkey (21) and human (53) pancreatic islets to kisspeptin stimulates glucose-induced insulin secretion. Nonetheless, contradictory findings have been found in mice that suggest that Kiss1r signaling in $\beta$-cells suppresses glucose-induced insulin secretion (69). In addition to the pancreatic and hepatic action of kisspeptin, we cannot rule out that the decrease in lean mass observed in kisspeptin signaling deficient mice contributes to the different glucose tolerance compared with their WT counterparts. In addition to peripheral actions, a central effect of kisspeptin in glucose homeostasis is also possible, given that Kiss1 neurons co-express insulin receptors $(22,23,70)$; however, the specific deletion of insulin receptor (alone or jointly with leptin receptor, which share common intracellular pathways) does not affect glucose homeostasis (23). Nevertheless, whether Kiss1 neurons modulate the activity of other insulin sensitive neurons cannot be excluded.

\section{Conclusions and perspectives}

Reproduction is energy demanding, therefore, the neuroendocrine mechanisms regulating reproductive function and energy balance are reciprocally linked. During the last decade, major advance has been made in the understanding of the central mechanisms synchronizing these two functions and the progress in the generation of genetic mouse models and viral techniques has greatly advanced our knowledge of the neuroendocrine circuitries underlying this effect. However, the complexity of these networks and the controversial findings in the field prevented the complete understanding of the neuronal pathways synchronizing reproductive activity with energy reserves. The role of Kiss1 neurons in the regulation of the HPG axis has been well depicted and the role of Kiss1 neurons as metabolic gatekeepers for reproductive success thoroughly characterized. In this review, we summarized the current evidence supporting a bidirectional role of Kiss1 neurons in the control of reproduction and metabolism. On one hand, Kiss $1^{\mathrm{ARC}}$ neurons are direct targets of central and peripheral metabolic cues, which form an essential regulatory element of the HPG axis from early stages of development. On the other hand, they actively control metabolic function through, at least, direct connections with AgRP and POMC neurons in the ARC, although additional (yet unidentified) actions onto neuronal networks that regulate energy balance are likely, given the widespread location of Kiss1 projections throughout the brain.

Interestingly, a recently identified role of Kiss $1^{A R C}$ neurons in the transmission of circadian rhythms has also been suggested to impinge energy balance due to the loss of the circadian (nocturnal) pattern of feeding behavior. A number of studies in rodent models have documented the importance of time restricted feeding, where the same number of calories can lead to normal $\mathrm{BW}$ if consumed over a short period of time or to obesity if consumed spread throughout the day. The remaining question in this action relates to whether Kiss1 neurons receive direct regulation from the $\mathrm{SCN}$, control downstream targets of the SCN or have their own circadian pattern that regulate feeding (and locomotion).

As described in this review, the nature of the predominant mechanism underlying the metabolic role of Kiss1 neurons is also a matter of debate. While some studies point to an effect on food intake, negative data have also been described in several species, including the human, which leads to the speculation that this effect is highly dependent on age, sex and hormonal milieu. This may suggest that the control of energy expenditure, which is consistently decreased in the absence of kisspeptin signaling and Kiss1 neuron silencing, is the predominant pathway in the metabolic influence of Kiss1 neurons. Whether this is an indirect consequence of decreased locomotion activity in the absence of functional Kiss1 neurons, or a direct action on specific brain areas regulating the activation of the BAT, will require further investigation.

Finally, one of the most important unresolved questions in the metabolic action of Kiss1 neurons relates to the contribution of kisspeptin per se vs its co-transmitters in this action. The fact that the expression of Kiss1r in the brain is limited and highly specific to some neuronal groups (i.e. GnRH neurons) and the greater metabolic phenotype after Kiss $1^{\text {ARC }}$ silencing compared with Kiss $1 \mathrm{rKO}$ mice strongly suggests that additional factors are at play in the metabolic role of Kiss1 neurons.

Overall, compelling evidence is mounting supporting a metabolic role of kisspeptin (and Kiss1 neurons). Besides increasing our understanding of the central mechanisms that govern energy balance, characterizing this effect in detail will be of critical importance in order to assess

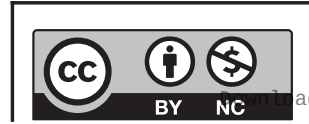

This work is licensed under a Creative Commons Attribution-NonCommercial 4.0 International License. ded from Bioscientifica.com at 04/26/2023 07:54:03AM 
possible metabolic risks in patients undergoing kisspeptin treatments, as in vitro fertilization techniques and novel approaches to increase sexual drive are successfully using kisspeptin as the main elicitor of the activation of the HPG axis in humans. To date, no metabolic alterations have been described in clinical and preclinical kisspeptinbased treatments; however, as the field progresses, there is a high probability that the description of metabolic implications will occur.

\section{Declaration of interest}

The authors declare that there is no conflict of interest that could be perceived as prejudicing the impartiality of this review.

\section{Funding}

This work was supported by Grants R01HD090151, R21HD095383 by the Eunice Kennedy Shriver National Institute of Child Health and Human Development (NICHD) and National Institute of Health (NIH) to V M N and by the International Brain Research Organization (IBRO) Fellowship and the Lalor Foundation Research Fellowship to R T.

\section{References}

1 Seminara SB, Messager S, Chatzidaki EE, Thresher RR, Acierno JS, Shagoury JK, Bo-Abbas Y, Kuohung W, Schwinof KM, Hendrick AG, et al. The GPR54 gene as a regulator of puberty. New England Journal of Medicine 2003349 1614-1627. (https://doi.org/10.1056/ NEJMoa035322)

2 Topaloglu AK, Tello JA, Kotan LD, Ozbek MN, Yilmaz MB, Erdogan S, Gurbuz F, Temiz F, Millar RP \& Yuksel B. Inactivating KISS1 mutation and hypogonadotropic hypogonadism. New England Journal of Medicine 2012366 629-635. (https://doi.org/10.1056/ NEJMoa1111184)

3 Smith JT, Cunningham MJ, Rissman EF, Clifton DK \& Steiner RA. Regulation of Kiss1 gene expression in the brain of the female mouse. Endocrinology 2005146 3686-3692. (https://doi.org/10.1210/ en.2005-0488)

4 Smarr BL, Morris E \& De La Iglesia HO. The dorsomedial suprachiasmatic nucleus times circadian expression of Kiss 1 and the luteinizing hormone surge. Endocrinology 2012153 2839-2850. (https://doi.org/10.1210/en.2011-1857)

5 Herbison AE. Estrogen positive feedback to gonadotropinreleasing hormone (GnRH) neurons in the rodent: the case for the rostral periventricular area of the third ventricle (RP3V). Brain Research Reviews 200857 277-287. (https://doi.org/10.1016/j. brainresrev.2007.05.006)

6 Robertson JL, Clifton DK, de la Iglesia HO, Steiner RA \& Kauffman AS. Circadian regulation of Kiss1 neurons: implications for timing the preovulatory gonadotropin-releasing hormone/ luteinizing hormone surge. Endocrinology $20091503664-3671$. (https://doi.org/10.1210/en.2009-0247)

7 Navarro VM \& Tena-Sempere M. Neuroendocrine control by kisspeptins: role in metabolic regulation of fertility. Nature Reviews: Endocrinology 20118 40-53. (https://doi.org/10.1038/ nrendo.2011.147)

8 Clarkson J, Han SY, Piet R, Mclennan T, Kane G, Ng J, Porteous R, Joon S, Colledge W, Iremonger K, et al. Definition of the hypothalamic GnRH pulse generator in mice. PNAS 2017114 e10216-e10223. (https://doi.org/10.1073/pnas.1713897114)
9 Cravo RM, Margatho LO, Osborne-Lawrence S, Donato J, Atkin S, Bookout AL, Rovinsky S, Frazão R, Lee CE, Gautron L, et al. Characterization of Kiss1 neurons using transgenic mouse models. Neuroscience 2011173 37-56. (https://doi.org/10.1016/j. neuroscience.2010.11.022)

10 Nestor CC, Qiu J, Padilla SL, Zhang C, Bosch MA, Fan W, Aicher SA, Palmiter RD, Rønnekleiv OK \& Kelly MJ. Optogenetic stimulation of arcuate nucleus Kiss1 neurons reveals a steroid-dependent glutamatergic input to POMC and AgRP neurons in male mice. Molecular Endocrinology 201630 630-644. (https://doi.org/10.1210/ me.2016-1026)

11 Qiu J, Nestor CC, Zhang C, Padilla SL, Palmiter RD, Kelly MJ \& Rønnekleiv OK. High-frequency stimulation-induced peptide release synchronizes arcuate kisspeptin neurons and excites GnRH neurons. eLife 20165 e16246. (https://doi.org/10.7554/eLife.16246)

12 Kim J, Semaan SJ, Clifton DK, Steiner RA, Dhamija S \& Kauffman AS. Regulation of Kiss1 expression by sex steroids in the amygdala of the rat and mouse. Endocrinology 2011152 2020-2030. (https://doi. org/10.1210/en.2010-1498)

13 Fergani C, Leon S, Padilla SL, Verstegen AM, Palmiter RD \& Navarro VM. NKB signalling in the medial amygdala stimulates gonadotropin release in a kisspeptin-independent manner in female mice. eLife 20187 e40476. (https://doi.org/10.7554/eLife.40476)

14 Lass G, Li XF, de Burgh RA, He W, Kang Y, Yeo S-H, Sinnett-Smith LC, Manchishi SM, Colledge WH, Lightman SL, et al. Optogenetic stimulation of kisspeptin neurones within the posterodorsal medial amygdala increases LH pulse frequency in female mice. Journal of Neuroendocrinology 201924 e12823. (https://doi.org/10.1111/jne.12823)

15 Aggarwal S, Tang C, Sing K, Kim HW, Millar RP \& Tello JA. Medial amygdala Kiss1 neurons mediate female pheromone stimulation of luteinizing hormone in male mice. Neuroendocrinology 2019108 172-189. (https://doi.org/10.1159/000496106)

16 Adekunbi DA, Li XF, Li S, Adegoke OA, Iranloye BO, Morakinyo AO, Lightman SL, Taylor PD, Poston L \& Byrne KTO. Role of amygdala kisspeptin in pubertal timing in female rats. PLOS ONE 201712 e0183596. (https://doi.org/10.1371/journal.pone.0183596)

17 Tsutsumi R \& Webster NJG. GnRH pulsatility, the pituitary response and reproductive dysfunction. Endocrine Journal 200956 729-737. (https://doi.org/10.1507/endocrj.k09e-185)

18 Metwally M, Li TC \& Ledger WL. The impact of obesity on female reproductive function. Obesity Reviews 20078 515-523. (https://doi. org/10.1111/j.1467-789X.2007.00406.x)

19 Castellano JM, Navarro VM, Fernandez-Fernandez R, Nogueiras R, Tovar S, Roa J, Vazquez MJ, Vigo E, Casanueva FF, Aguilar E, et al. Changes in hypothalamic KiSS-1 system and restoration of pubertal activation of the reproductive axis by kisspeptin in undernutrition. Endocrinology 2005146 3917-3925. (https://doi.org/10.1210/ en.2005-0337)

20 Luque RM, Kineman RD \& Tena-Sempere M. Regulation of hypothalamic expression of KiSS-1 and GPR54 genes by metabolic factors: analyses using mouse models and a cell line. Endocrinology 2007148 4601-4611. (https://doi.org/10.1210/en.2007-0500)

21 Wahab F, Ullah F, Chan YM, Seminara SB \& Shahab M. Decrease in hypothalamic Kiss1 and Kiss1r expression: a potential mechanism for fasting-induced suppression of the HPG axis in the adult male rhesus monkey (Macaca mulatta). Hormone and Metabolic Research 201143 81-85. (https://doi.org/10.1055/s-0030-1269852)

22 Qiu X, Dowling AR, Marino JS, Faulkner LD, Bryant B, Brüning JC, Elias CF \& Hill JW. Delayed puberty but normal fertility in mice with selective deletion of insulin receptors from kiss1 cells. Endocrinology 2013154 1337-1348. (https://doi.org/10.1210/en.2012-2056)

23 Qiu X, Dao H, Wang M, Heston A, Garcia KM, Sangal A, Dowling AR, Faulkner LD, Molitor SC, Elias CF, et al. Insulin and leptin signaling interact in the mouse Kiss1 neuron during the peripubertal period. PLoS ONE 201510 e0121974. (https://doi.org/10.1371/journal. pone.0121974)

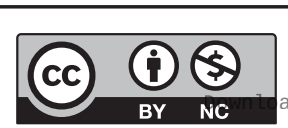

This work is licensed under a Creative Commons Attribution-NonCommercial 4.0 International License. ded from Bioscientifica.com at 04/26/2023 07:54:03AM 
24 Barsh GS \& Schwartz MW. Genetic approaches to studying energy balance: perception and integration. Nature Reviews: Genetics 20023 589-600. (https://doi.org/10.1038/nrg862)

25 Timper K \& Brüning JC. Hypothalamic circuits regulating appetite and energy homeostasis: pathways to obesity. Disease Models and Mechanisms 201710 679-689. (https://doi.org/10.1242/ dmm.026609)

26 Hill JW, Elmquist JK \& Elias CF. Hypothalamic pathways linking energy balance and reproduction. American Journal of Physiology: Endocrinology and Metabolism 2008294 E827-E832. (https://doi. org/10.1152/ajpendo.00670.2007)

27 Evans JJ \& Anderson GM. Balancing ovulation and anovulation: integration of the reproductive and energy balance axes by neuropeptides. Human Reproduction Update 201218 313-332. (https://doi.org/10.1093/humupd/dms004)

28 Brown KS, Gentry RM \& Rowland NE. Central injection in rats of alpha-melanocyte-stimulating hormone analog: effects on food intake and brain Fos. Regulatory Peptides 199878 89-94. (https://doi. org/10.1016/s0167-0115(98)00127-x)

29 McMinn JE, Wilkinson CW, Havel PJ, Woods SC \& Schwartz MW. Effect of intracerebroventricular alpha-MSH on food intake, adiposity, c-Fos induction, and neuropeptide expression. American Journal of Physiology: Regulatory, Integrative and Comparative Physiology 2000279 R695-R703. (https://doi.org/10.1152/ ajpregu.2000.279.2.R695)

30 Bai FL, Yamano M, Shiotani Y, Emson PC, Smith AD, Powell JF \& Tohyama M. An arcuato-paraventricular and -dorsomedial hypothalamic neuropeptide Y-containing system which lacks noradrenaline in the rat. Brain Research 1985331 172-175. (https:// doi.org/10.1016/0006-8993(85)90730-9)

31 Morley JE, Levine AS, Gosnell BA, Kneip J \& Grace M. Effect of neuropeptide $\mathrm{Y}$ on ingestive behaviors in the rat. American Journal of Physiology 1987252 R599-R609. (https://doi.org/10.1152/ ajpregu.1987.252.3.R599)

32 Leibowitz SF. Brain neuropeptide Y: an integrator of endocrine, metabolic and behavioral processes. Brain Research Bulletin 199127 333-337. (https://doi.org/10.1016/0361-9230(91)90121-y)

33 Sandrock M, Schulz A, Merkwitz C, Schöneberg T, SpanelBorowski K \& Ricken A. Reduction in corpora lutea number in obese melanocortin-4-receptor-deficient mice. Reproductive Biology and Endocrinology 20097 24. (https://doi.org/10.1186/1477-7827-7-24)

34 Doulla M, Mcintyre AD, Hegele RA \& Gallego PH. A novel MC4R mutation associated with childhood-onset obesity: a case report. Paediatrics and Child Health 201410 515-518. (https://doi. org/10.1093/pch/19.10.515)

35 Chen X, Huang L, Tan HY, Li H, Wan Y, Cowley M, Veldhuis JD \& Chen C. Deficient melanocortin-4 receptor causes abnormal reproductive neuroendocrine profile in female mice. Reproduction 2017153 267-276. (https://doi.org/10.1530/REP-16-0341)

36 Gonzalez MI, Celis ME, Hole DR \& Wilson CA. Interaction of oestradiol, $\alpha$-melanotrophin and noradrenaline within the ventromedial nucleus in the control of female sexual behaviour. Neuroendocrinology 199358 218-226. (https://doi. org/10.1159/000126536)

37 Van der Ploeg LHT, Martin WJ, Howard AD, Nargund RP, Austin CP, Guan X, Drisko J, Cashen D, Sebhat I, Patchett AA, et al. A role for the melanocortin 4 receptor in sexual function. PNAS 200299 11381-11386. (https://doi.org/10.1073/pnas.172378699)

38 Wessells H, Levine N, Hadley ME, Dorr R \& Hruby V. Melanocortin receptor agonists, penile erection, and sexual motivation: human studies with Melanotan II. International Journal of Impotence Research 200012 (Supplement 4) S74-S79. (https://doi.org/10.1038/ sj.ijir.3900582)

39 Israel DD, Sheffer-Babila S, de Luca C, Jo YH, Liu SM, Xia Q, Spergel DJ, Dun SL, Dun NJ \& Chua SC. Effects of leptin and melanocortin signaling interactions on pubertal development and reproduction. Endocrinology 2012153 2408-2419. (https://doi. org/10.1210/en.2011-1822)

40 Roa J \& Herbison AE. Direct regulation of GnRH neuron excitability by arcuate nucleus POMC and NPY neuron neuropeptides in female mice. Endocrinology 2012153 5587-5599. (https://doi.org/10.1210/ en.2012-1470)

41 Manfredi-Lozano M, Roa J, Ruiz-Pino F, Piet R, Garcia-Galiano D, Pineda R, Zamora A, Leon S, Sanchez-Garrido MA, Romero-Ruiz A, et al. Defining a novel leptin-melanocortin-kisspeptin pathway involved in the metabolic control of puberty. Molecular Metabolism 20165 844-857. (https://doi.org/10.1016/j.molmet.2016.08.003)

42 Padilla SL, Qiu J, Nestor CC, Zhang C, Smith AW, Whiddon BB, Rønnekleiv OK, Kelly MJ \& Palmiter RD. AgRP to Kiss1 neuron signaling links nutritional state and fertility. PNAS $2017 \mathbf{1 1 4}$ 2413-2418. (https://doi.org/10.1073/pnas.1621065114)

43 Tolson KP, Garcia C, Yen S, Simonds S, Stefanidis A, Lawrence A, Smith JT \& Kauffman AS. Impaired kisspeptin signaling decreases metabolism and promotes glucose intolerance and obesity. Journal of Clinical Investigation 2014124 3075-3079. (https://doi.org/10.1172/ JCI71075)

44 De Bond J-AP, Tolson KP, Nasamran C, Kauffman AS, Smith JT. Unaltered hypothalamic metabolic gene expression in Kiss1r knockout mice despite obesity and reduced energy expenditure. Journal of Neuroendocrinology 201628 10.1111. (https://doi. org/10.1111/jne.12430)

45 Velasco I, León S, Barroso A, Ruiz-Pino F, Heras V, Torres E, León M, Ruohonen ST, García-Galiano D, Romero-Ruiz A, et al. Gonadal hormone-dependent vs. -independent effects of kisspeptin signaling in the control of body weight and metabolic homeostasis. Metabolism: Clinical and Experimental 201998 84-94. (https://doi. org/10.1016/j.metabol.2019.06.007)

46 de Roux N, Genin E, Carel JC, Matsuda F, Chaussain JL \& Milgrom E. Hypogonadotropic hypogonadism due to loss of function of the KiSS1-derived peptide receptor GPR54. PNAS 2003100 10972-10976. (https://doi.org/10.1073/pnas.1834399100)

47 Celis ME. Release of LH in response to alpha-MSH administration. Acta Physiologica et Pharmacologica Latinoamericana 198535 281-290.

48 García-Galiano D, Navarro VM, Roa J, Ruiz-Pino F, SánchezGarrido MA, Pineda R, Castellano JM, Romero M, Aguilar E, Gaytán F, et al. The anorexigenic neuropeptide, nesfatin-1, is indispensable for normal puberty onset in the female rat. Journal of Neuroscience 201030 7783-7792. (https://doi.org/10.1523/ JNEUROSCI.5828-09.2010)

49 Stengel A, Wang L, Goebel-Stengel M \& Tache Y. Centrally injected kisspeptin reduces food intake by increasing meal intervals in mice. NeuroReport 201122 253-257. (https://doi.org/10.1097/ WNR.0b013e32834558df)

50 Talbi R, Laran-Chich M-P, Magoul R, El Ouezzani S \& Simonneaux V. Kisspeptin and RFRP-3 differentially regulate food intake and metabolic neuropeptides in the female desert jerboa. Scientific Reports 20166 36057. (https://doi.org/10.1038/srep36057)

51 Saito R, Tanaka K, Nishimura H, Nishimura K, Sonoda S, Ueno H, Motojima Y, Yoshimura M, Maruyama T, Yamamoto Y, et al. Centrally administered kisspeptin suppresses feeding via nesfatin-1 and oxytocin in male rats. Peptides 2019112 114-124. (https://doi. org/10.1016/j.peptides.2018.12.003)

52 Thompson EL, Patterson M, Murphy KG, Smith KL, Dhillo WS, Todd JF, Ghatei MA \& Bloom SR. Central and peripheral administration of kisspeptin-10 stimulates the hypothalamicpituitary-gonadal axis. Journal of Neuroendocrinology 200416 850-858. (https://doi.org/10.1111/j.1365-2826.2004.01240.x)

53 Izzi-Engbeaya C, Comninos AN, Clarke SA, Jomard A, Yang L, Jones S, Abbara A, Narayanaswamy S, Eng PC, Papadopoulou D, et al. The effects of kisspeptin on $\beta$-cell function, serum metabolites and appetite in humans. Diabetes, Obesity and Metabolism 201820 2800-2810. (https://doi.org/10.1111/dom.13460) https://ec.bioscientifica.com https://doi.org/10.1530/EC-20-0068 (c) 2020 The authors Published by Bioscientifica Ltd
This work is licensed under a Creative Commons Attribution-NonCommercial 4.0 International License. ded from Bioscientifica,com at 04/26/2023 07:54:03AM 
54 Dong TS, Vu JP, Oh S, Sanford D, Pisegna JR \& Germano P. Intraperitoneal treatment of kisspeptin suppresses appetite and energy expenditure and alters gastrointestinal hormones in mice. Digestive Diseases and Sciences 2019 [epub]. (https://doi.org/10.1007/ s10620-019-05950-7)

55 Navarro VM, Castellano JM, Fernández-Fernández R, Tovar S, Roa J, Mayen A, Nogueiras R, Vazquez MJ, Barreiro ML, Magni P, et al. Characterization of the potent luteinizing hormone Releasin activity of KiSS-1 peptide, the natural ligand of GPR54. Endocrinology 2005 146 156-163. (https://doi.org/10.1210/en.2004-0836)

56 Fenselau H, Campbell JN, Verstegen AMJ, Madara JC, Xu J, Shah BP, Resch JM, Yang Z, Mandelblat-Cerf Y, Livneh Y, et al. A rapidly acting glutamatergic $\mathrm{ARC} \rightarrow \mathrm{PVH}$ satiety circuit postsynaptically regulated by $\alpha$-MSH. Nature Neuroscience 201720 42-51. (https://doi.org/10.1038/ nn.4442)

57 Padilla SL, Perez JG, Ben-hamo M, Bussi IL, Palmiter RD \& Iglesia HO De. Kisspeptin neurons in the arcuate nucleus of the hypothalamus orchestrate circadian rhythms and article kisspeptin neurons in the arcuate nucleus of the hypothalamus orchestrate circadian rhythms and metabolism. Current Biology 2019 1.e7-12.e7. (https://doi. org/10.1016/j.cub.2019.01.022)

58 Yeo SH \& Herbison AE. Projections of arcuate nucleus and rostral periventricular kisspeptin neurons in the adult female mouse brain. Endocrinology 2011152 2387-2399. (https://doi.org/10.1210/ en.2011-0164)

59 Higo S, Iijima N \& Ozawa H. Characterisation of Kiss1r (Gpr54)expressing neurones in the arcuate nucleus of the female rat hypothalamus. Journal of Neuroendocrinology 201729 [epub]. (https:// doi.org/10.1111/jne.12452)

60 Fu LY \& Van den Pol AN. Kisspeptin directly excites anorexigenic proopiomelanocortin neurons but inhibits orexigenic neuropeptide Y cells by an indirect synaptic mechanism. Journal of Neuroscience 201030 10205-10219. (https://doi.org/10.1523/ JNEUROSCI.2098-10.2010)

61 Cázarez-Márquez F, Milesi S, Laran-Chich M, Klosen P, Kalsbeek A \& Simonneauex V. Kisspeptin and RFRP3 modulate body mass in Phodopus sungorus via two different neuroendocrine pathways.
Journal of Neuroendocrinology 201931 e12710. (https://doi. org/10.1111/jne.12710)

62 Andermann ML \& Lowell BB. Toward a wiring diagram understanding of appetite control. Neuron 201795 757-778. (https:// doi.org/10.1016/j.neuron.2017.06.014)

63 Tolson KP, Garcia C, Delgado I, Marooki N \& Kauffman AS. Metabolism and energy expenditure, but not feeding or glucose tolerance, are impaired in young kiss1r ko female mice. Endocrinology 2016157 4192-4199. (https://doi.org/10.1210/en.2016-1501)

64 Qiu J, Rivera HM, Bosch MA, Padilla SL, Stincic TL, Palmiter RD, Kelly MJ \& Rønnekleiv OK. Estrogenic-dependent glutamatergic neurotransmission from kisspeptin neurons governs feeding circuits in females. eLife 20187 08. (https://doi.org/10.7554/eLife.35656)

65 Stincic TL, Grachev P, Bosch MA, Rønnekleiv OK \& Martin J. Estradiol drives the anorexigenic activity of proopiomelanocortin neurons in female mice. eNeuro 20185 ENEURO.0103-18.2018. (https://doi.org/10.1523/ENEURO.0103-18.2018)

66 Morrison SF, Madden CJ \& Tupone D. Central neural regulation of brown adipose tissue thermogenesis and energy expenditure. Cell Metabolism 201419 741-756. (https://doi.org/10.1016/j. cmet.2014.02.007)

67 Tolson KP, Marooki N, De Bond JP, Walenta E, Stephens SBZ, Liaw RB, Savur R, Wolfe A, Oh DY, Smith JT, et al. Conditional knockout of kisspeptin signaling in brown adipose tissue increases metabolic rate and body temperature and lowers body weight. FASEB Journal 2020 34 107-121. (https://doi.org/10.1096/fj.201901600R)

68 Hauge-Evans AC, Richardson CC, Milne HM, Christie MR, Persaud SJ \& Jones PM. A role for kisspeptin in islet function. Diabetologia 2006 49 2131-2135. (https://doi.org/10.1007/s00125-006-0343-z)

69 Song WJ, Mondal P, Wolfe A, Alonso LC, Stamateris R, Ong BWT, Lim OC, Yang KS, Radovick S, Novaira HJ, et al. Glucagon regulates hepatic Kisspeptin1 to impair insulin secretion. Cell Metabolism 2014 19 667-681. (https://doi.org/10.1016/j.cmet.2014.03.005)

70 Backholer K, Bowden M, Gamber K, Bjørbæk C, Iqbal J \& Clarke IJ. Melanocortins mimic the effects of leptin to restore reproductive function in lean hypogonadotropic ewes. Neuroendocrinology 201091 27-40. (https://doi.org/10.1159/000260060)

Received in final form 16 April 2020

Accepted 28 April 2020

Accepted Manuscript published online 29 April 2020
This work is licensed under a Creative Commons Attribution-NonCommercial 4.0 International License. ded from Bioscientifica.com at 04/26/2023 07:54:03AM 